\title{
Combined effects of doxorubicin and STI571 on growth, differentiation and apoptosis of CML cell line K562
}

\author{
Justyna Jakubowska ${ }^{1}$, Marta Stasiak ${ }^{2}$, Agata Szulawska ${ }^{1}$, Andrzej Bednarek ${ }^{3}$ \\ and Malgorzata Czyz ${ }^{1 凶}$ \\ ${ }^{1}$ Department of Molecular Biology of Cancer, ${ }^{2}$ Department of Molecular and Medical Biophysics, and \\ ${ }^{3}$ Department of Molecular Cancerogenesis, Medical University of Lodz, Łódź, Poland
}

Received: 09 July, 2007; revised: 16 September, 2007; accepted: 05 October, 2007

avilable on-line: 25 October, 2007

\begin{abstract}
STI571 (imatinib mesylate; Gleevec ${ }^{\circledR}$ ) is an inhibitor that targets the tyrosine kinase activity of Bcr-Abl present in chronic myelogenous leukemia (CML) cells. Some preclinical studies have demonstrated that the combination of STI571 with chemotherapeutic drugs results in enhanced toxicity in Bcr-Abl-positive leukemias. We investigated the potential benefit of using STI571 to down-regulate Bcr-Abl activity for the enhancement of doxorubicin anti-proliferative action in K562 cell line derived from blast crisis of CML. At low concentrations of both drugs (40 nM doxorubicin combined with STI571 in the range of 100-150 nM), the antiproliferative effects were mainly due to cellular differentiation as assessed by benzidine staining for hemoglobin synthesis level and real-time PCR for $\gamma$-globin expression. Higher concentrations of STI571 used in combinations with doxorubicin caused mainly apoptosis as shown by DNA degradation and nuclear fragmentation visualized by fluorescence microscopy after DAPI staining, changes in cell morphology observed after Giemza-May Grünwald staining and cellular membrane organization estimated by flow cytometry after Annexin V staining. As compared with either drug alone, cotreatment with STI571 and DOX induced stronger cellular responses. A low concentration of STI571 in combination with a low concentration of DOX might be tested as an alternative approach to increasing the efficacy of chemotherapy against CML.
\end{abstract}

Keywords: K562 cells, anticancer drugs, STI571, doxorubicin, differentiation, apoptosis

\section{INTRODUCTION}

A chimeric oncogene, p210 Bcr-Abl is present in almost all cases of chronic myelogenous leukemia (CML). This tyrosine kinase activates a number of downstream cell signaling pathways, resulting in increased cell proliferation, arrested differentiation, and resistance to apoptosis induced by chemotherapeutics (Bedi et al., 1995). STI571 (imatinib mesylate; Gleevec $^{\circledR}$ ) inhibits Bcr-Abl activity by occupying its ATP-binding pocket (Schindler et al., 2000). Although highly active in early stages of CML, STI571 is unable to eradicate malignant progenitors and several patients develop drug resistance after long-time use. It is of great importance to develop an alternative strategy to overcome both STI571 resistance and the reduced sensitivity to DNA-damaging drugs in CML cells. One of the candidates for the combined therapy could be doxorubicin (DOX). The anticancer activity of DOX is broadly used and the mechanisms of its action are defined (Minotti et al., 2004). DOX is not applied during the blast crisis of CML (Faderl et al., 1999) mainly because it fails to induce apoptosis of CML cells, similarly to many other DNA-damaging drugs. It has been shown that other antileukemic drugs like interferon-alpha (IFN- $\alpha$ ), hydroxyurea (HU), daunorubicin (DNR) or cytosine arabinoside (ara-C) exert either synergistic (ara-C) or additive (DNR, IFN) or even antagonistic (HU) effects in proliferation assays performed in Bcr-Abl-expressing cell

$\square$ Corresponding author: Malgorzata Czyz, Department of Molecular Biology of Cancer, Medical University of Lodz, Mazowiecka 6/8, 92-215 Łódź, Poland; tel./fax (48) 42678 4277; e-mail: mczyz@csk.umed.lodz.pl

Abbreviations: ALL, acute lymphoblastic leukemia; ara-C, cytosine arabinoside; $\mathrm{CML}$, chronic myelogenous leukemia; DAPI, 4',6-diamidino-2-phenylindole; DMSO, dimethylsulfoxide; DOX, doxorubicin; PBS, phosphate-buffered saline; PI, propidium iodide; TBE, Tris/borate/EDTA buffer. 
lines (Thiesing et al., 2000). Arsenic trioxide (ATO) effectively synergized with STI571 in K562 cells and it was shown that binding of STI571 to the Bcr-Abl kinase is crucial for the collaboration of those drugs (Du et al., 2006). Our study was undertaken to compare the effects of STI571 alone and in combination with DOX on K562 cells. We hypothesized that the molecular mechanisms of inhibition of cellular proliferation by STI571 and DOX are largely dependent on concentrations of both drugs used in combinations. We investigated the effects of both drugs on differentiation as measured by benzidine staining and erythroid gene expression and apoptosis visualized by morphological changes or externalization of phosphatidylserine. One of the major aims of our study was to examine whether STI571 would sensitize the Bcr-Abl-positive K562 cells to cell death induced by DOX.

\section{MATERIALS AND METHODS}

Drugs. Doxorubicin was kindly provided by Dr. Irena Oszczapowicz and Mrs. Malgorzata Wasowska from the Institute of Biotechnology and Antibiotics (Warszawa, Poland). STI571 (imatinib mesylate; Novartis Pharmaceuticals) was a gift of Professor Janusz Blasiak. Stock solutions $(1 \mathrm{mM})$ of each compound, DOX in sterile water and STI571 in DMSO, were stored in the dark at $-20^{\circ} \mathrm{C}$ and diluted in RPMI 1640 medium immediately before use.

Cell culture conditions, viability and proliferation assay. The Bcr-Abl-positive human K562 cell line was maintained in a humidified atmosphere of $5 \% \mathrm{CO}_{2}$ at $37^{\circ} \mathrm{C}$ in RPMI 1640 (Gibco, Scotland, UK, supplemented with $10 \%$ heat-inactivated fetal bovine serum (FBS, Gibco, Scotland, UK) and $50 \mu \mathrm{g} / \mathrm{ml}$ gentamycin (Polfa-Tarchomin, Poland). For experiments, K562 cells were seeded at $4 \times 10^{4} / \mathrm{ml}$ and $24 \mathrm{~h}$ later either each drug alone or their combination was added. Cell proliferation and viability were determined by using Trypan Blue dye exclusion test as reported previously (Czyz et al., 2005). Each experiment was conducted in triplicate and repeated at least three times.

Benzidine staining. The benzidine oxidation test was performed as described previously (Czyz et al., 2005). Cells were collected at day 4, washed twice with ice-cold PBS and resuspended in $0.9 \%$ $\mathrm{NaCl}$. Benzidine solution, containing $0.2 \%(\mathrm{w} / \mathrm{v})$ tetramethylbenzidine (Sigma) in $0.5 \mathrm{M}$ acetic acid and $0.6 \% \mathrm{H}_{2} \mathrm{O}_{2}$ was used to start the reaction. After $30 \mathrm{~min}$ incubation in darkness at room temperature, 200 cells were counted to determine the percentage of benzidine-positive cells, containing blue crystals. Each experiment was conducted in triplicate and repeated at least three times.
Quantitative real-time reverse transcription PCR. Total RNA and cDNA were prepared as described before (Szulawska et al., 2007). All real-time PCR reactions were optimized to obtain the best amplification kinetics. Amplification reactions were performed in a final volume of $20 \mu \mathrm{l}$ using $\mathrm{qPCR}^{\mathrm{TM}}$ Core Kit for Sybr ${ }^{\mathrm{TM}}$ Green I w/o dUTP (EUROGENTEC, Seraing B), $250 \mathrm{nM}$ primers and $25 \mathrm{ng}$ DNA template per reaction. Water was used as a no-template control. The PCR primer sequences were as follows: $\gamma$-globin: 5'-CCATAAAGCACCTGGATGATC-3' and 5'-ATCTGGAGGACAGGGCACTG-3', RPS17: 5'-TCGCTTCATCAGATGCGTGACATAACCTG-3' and 5'-AAGCGCGTGTGCGAGGAGATCG-3', $\beta$-microglobulin: 5'-TGAGTGCTGTCTCCATGTTTGA-3' and 5'-TCTGCTCCCCACCTCTAAGTTG-3'. Gene expression levels of $\gamma$-globin, RPS17, and $\beta$-microglobulin were tested using the Rotor-Gene 3000 Real-Time DNA analysis system (Corbett Research, Australia). Cycling conditions: 1 cycle at $95^{\circ} \mathrm{C}$ for $10 \mathrm{~min}, 40 \mathrm{cy}-$ cles at $95^{\circ} \mathrm{C}$ for $30 \mathrm{~s}, 55^{\circ} \mathrm{C}$ for $15 \mathrm{~s}(\gamma$-globin $)$ or $64^{\circ} \mathrm{C}$ for $15 \mathrm{~s}$ (RPS17) or $50^{\circ} \mathrm{C}$ for $15 \mathrm{~s}$ ( $\beta$-microglobulin), and $72^{\circ} \mathrm{C}$ for $30 \mathrm{~s}$. The relative expression was based on the expression ratio of the target gene ( $\gamma$-globin) versus reference genes (RPS17 and $\beta$-microglobulin). To calculate the relative expression ratios of single samples a mathematical model was used which included an efficiency correction for the real-time PCR efficiency of the individual transcripts (Pfaffl et al., 2002). Relative expression was calculated using REST (Corbett Research, Australia) software with the two reference genes mentioned above and untreated cultures as a control. Each experiment was conducted in triplicate and repeated at least three times.

Microscopic analysis of cell morphology. The cells were analyzed using a light microscope BX 41 (Olympus). Shortly, after 3 days of incubation with different concentrations of DOX and STI571 used alone or in combination, $2 \times 10^{4}$ cells were washed with PBS and resuspended in the same buffer. They were centrifuged on a slide and then stained with May-Grünwald and Giemsa (Sigma Diagnostics, St. Louis, MO, USA).

DAPI staining for nuclear fragmentation was performed after 3 days of culturing in the presence of drugs. Cells were fixed with $70 \%$ ethanol and stained with DAPI. Nuclei were visualized under fluorescence microscopy. Ten different fields were randomly selected for counting 300 cells. The percentage of cells with fragmented nuclei was then calculated.

Flow cytometry. Dual staining of cells with Annexin V and propidium iodide (PI) was used to assess apoptosis. After drug treatment for 24 or $48 \mathrm{~h}$, $1-5 \times 10^{5}$ cells were washed in cold PBS and resuspended in $200 \mu \mathrm{l}$ staining solution (Roche Diagnostics, Germany) containing $5 \mu \mathrm{l}$ of Annexin V-fluo- 
rescein isothiocyanate (FITC) and $5 \mu$ of propidium iodide. This method is a useful tool for distinguishing viable cells (unstained with either fluorochrome) from apoptotic cells (stained with Annexin V) and necrotic cells (stained with PI). The percentage of apoptotic cells was calculated as the sum of those stained with Annexin V alone (early apoptosis) and stained with both Annexin V and PI (late apoptosis).

Detection of DNA fragmentation. K562 cells were cultured as for benzidine staining with different concentrations of DOX and STI571. DNA was isolated on day 2 as described previously (Gong et al., 1994). Aliquots containing $8 \mu \mathrm{g}$ of each DNA sample were subjected to $1.2 \%(\mathrm{w} / \mathrm{v})$ agarose gel electrophoresis for $1.5 \mathrm{~h}$ at $0.09 \mathrm{~V} / \mathrm{m}$ in $1 \times$ TBE buffer. The gels were stained with ethidium bromide and photographed in UV light.

Statistical analysis. The data are expressed as means \pm standard deviation. Details are given in descriptions to Figures and Table.

\section{RESULTS}

Effects of STI571 and DOX on viability and growth of $\mathrm{K} 562$ cell line

All experiments were performed in K562 cells, a Bcr-Abl-positive human cell line derived from a

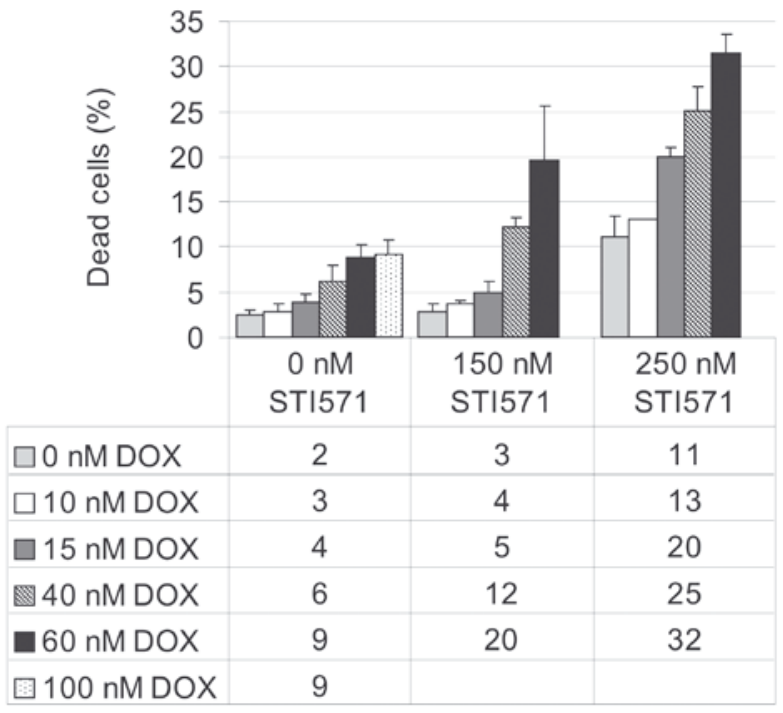

Figure 1. The effect of DOX used alone or in combination with STI571 on K562 cell viability.

Percentage of dead cells was estimated by Trypan Blue test after 3 days of culturing in the presence of various concentrations of DOX or STI571 used alone or in combination. Results from four independent experiments were averaged. Error bars represent standard deviation.

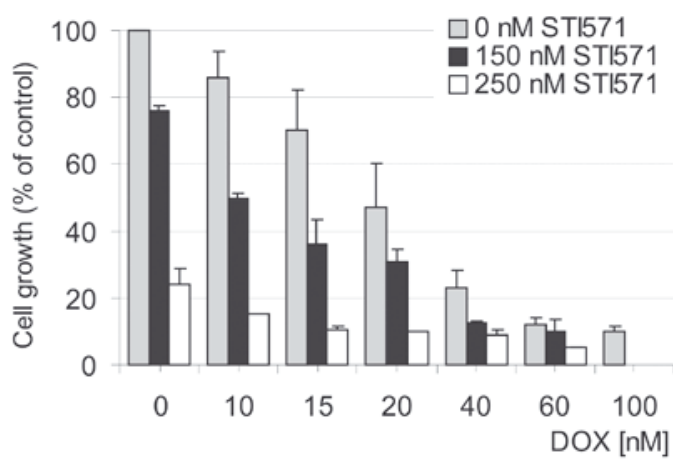

Figure 2. The cytostatic effect of DOX in combination with STI571 at low concentrations in K562 cells.

K562 cells were exposed simultaneously to various concentrations of STI571 and DOX for 3 days. Growth rates are expressed as the percentage of control. The data represent results from three independent experiments, each performed in triplicate. Error bars show standard deviation.

CML patient in blast crisis. Cell viability was scored on day 3 by Trypan Blue staining. As demonstrated in Fig. 1, K562 cell viability was reduced to $89 \%$ in cultures treated with $250 \mathrm{nM}$ STI571 used alone or to $75 \%$ in combination with $40 \mathrm{nM}$ DOX. DOX alone did not markedly affect cell viability even when used at $100 \mathrm{nM}$. STI571 at $250 \mathrm{nM}$ or lower used alone or in combination with $40 \mathrm{nM}$ DOX left more than $70 \%$ cells alive for 4 days (not shown).

The STI571- and/or DOX-induced growth inhibition of K562 cells is shown in Fig. 2. Proliferation was reduced to about $25 \%$ of the control level on day 3 with the use of $250 \mathrm{nM}$ STI571 or $40 \mathrm{nM}$ DOX. The $\mathrm{IC}_{50}$ values for STI571 and DOX alone were assessed following 3 days of incubation of K562 cells with different concentrations of the tested drugs; they were $200 \mathrm{nM}$ and $20 \mathrm{nM}$, respectively. Then, the combined effects of STI571 and DOX on cell differentiation and apoptosis were examined at drug concentrations close to those of their respective $\mathrm{IC}_{50}$ values.

\section{Effects of STI571 and/or DOX on cell differentiation}

Cell death was not the major cause for the decreased proliferation rates when STI571 at concentrations up to $250 \mathrm{nM}$ was used alone or in combination with DOX (Fig. 1). One of the possible explanations for cell growth arrest with no cytotoxic effect could be cell differentiation. To assess the erythroid differentiation-inducing effects of STI571 and/or DOX on K562 cells, first benzidine staining was used after 4 days of incubation with the drugs. Longer incubation with the drugs did not further significantly enhance hemoglobin production (not shown). STI571 at $150 \mathrm{nM}$, induced appearance of about $21 \%$ benzidine-positive K562 cells and DOX 
A
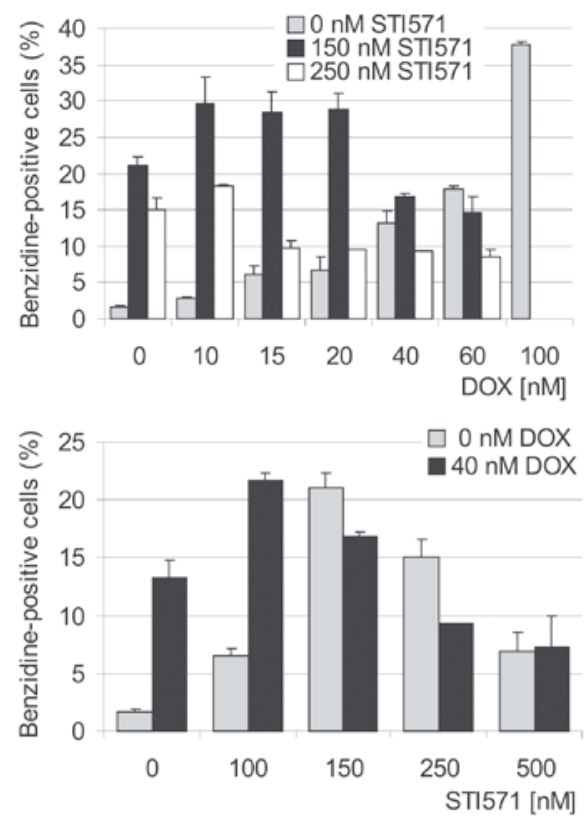

B

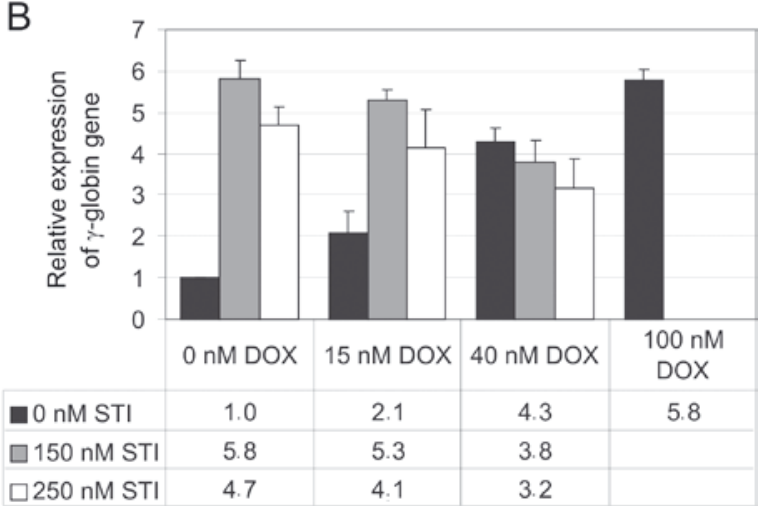

Figure 3. Enhanced erythroid differentiation of K562 cells observed for combinations of DOX and STI571 at low concentrations.

A. Erythroid differentiation is expressed as percentage of benzidine-positive (hemoglobin-containing) cells out of all viable cells. Data represent the mean \pm S.D. of three independent experiments. B. Quantitative real-time RT-PCR analysis of $\gamma$-globin mRNA from DOX and/or STI571treated K562 cells. RNA isolated from untreated cells or from cells treated with various concentrations of STI571 alone or in combination with various concentrations of DOX was reverse-transcribed and expression levels of $\gamma$ globin gene were assayed by quantitative real-time PCR. A fold increase of $\gamma$-globin mRNA in cultures treated with drugs compared with untreated cultures was then calculated using REST (Corbett Research, Australia) software. This experiment was repeated three times, and each point was in triplicate.

at $40 \mathrm{nM}$ about $13 \%$ (Fig. 3A). DOX used alone at higher concentrations caused an increase in the number of differentiated cells, up to $38 \%$ at $100 \mathrm{nM}$, whereas STI571 used alone at higher concentrations did not cause further cell differentiation. At $500 \mathrm{nM}$, STI571 induced only 7\% of benzidine-positive cells. STI571 and DOX used in combination at lower con- centrations significantly increased the percentage of differentiated cells. In this respect, the optimal concentrations of STI571 and DOX used in combined treatment of K562 cells were 100 to $150 \mathrm{nM}$ and 10 to $20 \mathrm{nM}$, respectively. The maximal effect, about $30 \%$ of differentiated cells, was observed in K562 cell cultures treated with $150 \mathrm{nM}$ STI571 in combination with 10 to $20 \mathrm{nM}$ DOX (Fig. 3A). This was about $50 \%$ more than observed in the presence of $150 \mathrm{nM}$ STI571 alone and 4-6 times more than for DOX alone used at those concentrations. DOX at 60 $\mathrm{nM}$ was already more efficient alone than in combination with $150 \mathrm{nM}$ STI571. Similar results were obtained when $\gamma$-globin gene expression was assessed by real-time PCR (Fig. 3B). The highest relative expression was obtained for $150 \mathrm{nM}$ STI571 and $100 \mathrm{nM}$ DOX used alone. Slightly lower expression was observed in cells treated with $150 \mathrm{nM}$ STI571 in combination with $15 \mathrm{nM}$ DOX, whereas a further increase of STI571 concentration in combination with DOX reduced the expression of the $\gamma$-globin gene. Erythroid differentiation, therefore, could contribute to the reduced proliferation observed in $\mathrm{K} 562$ cultures stimulated with tested drugs but only when they were used in combination and at low concentrations.

Effects of STI571 and DOX used in combination on apoptosis

It is often suggested that classification of cell death should be done by employing several assays and should be accompanied by morphological examination. Therefore, K562 cells were evaluated for evidence of apoptosis by different assays: I) translocation of phosphatidylserine to the outer plasma membrane by Annexin V staining and flow cytometry; II) microscopic analysis to identify morphological characteristics of apoptotic cells; III) detection of DNA fragmentation, and IV) DAPI staining. To assess whether combined treatment with DOX enhanced apoptosis induced by STI571, K562 cells were treated with various concentrations of STI571 alone or in combination with $40 \mathrm{nM}$ DOX and then

Table 1. Percentage of apoptotic cells measured by FACS after Annexin V staining.

The numbers indicate the percentage of cells being either in early or late stage of apoptosis (see Materials and Methods for details). The means \pm S.D. of two independent experiments are shown except for $100 \mathrm{nM}$ STI571 $\pm 40 \mathrm{nM}$ DOX where only one experiment was performed.

\begin{tabular}{lcc}
\hline & $0 \mathrm{nM}$ DOX & $40 \mathrm{nM}$ DOX \\
\hline 0 nM STI571 & $6 \pm 2$ & $7 \pm 2$ \\
100 nM STI571 & 8 & 14 \\
150 nM STI571 & $12 \pm 3$ & $14 \pm 2$ \\
250 nM STI571 & $16 \pm 2$ & $30 \pm 8$ \\
\hline
\end{tabular}


A

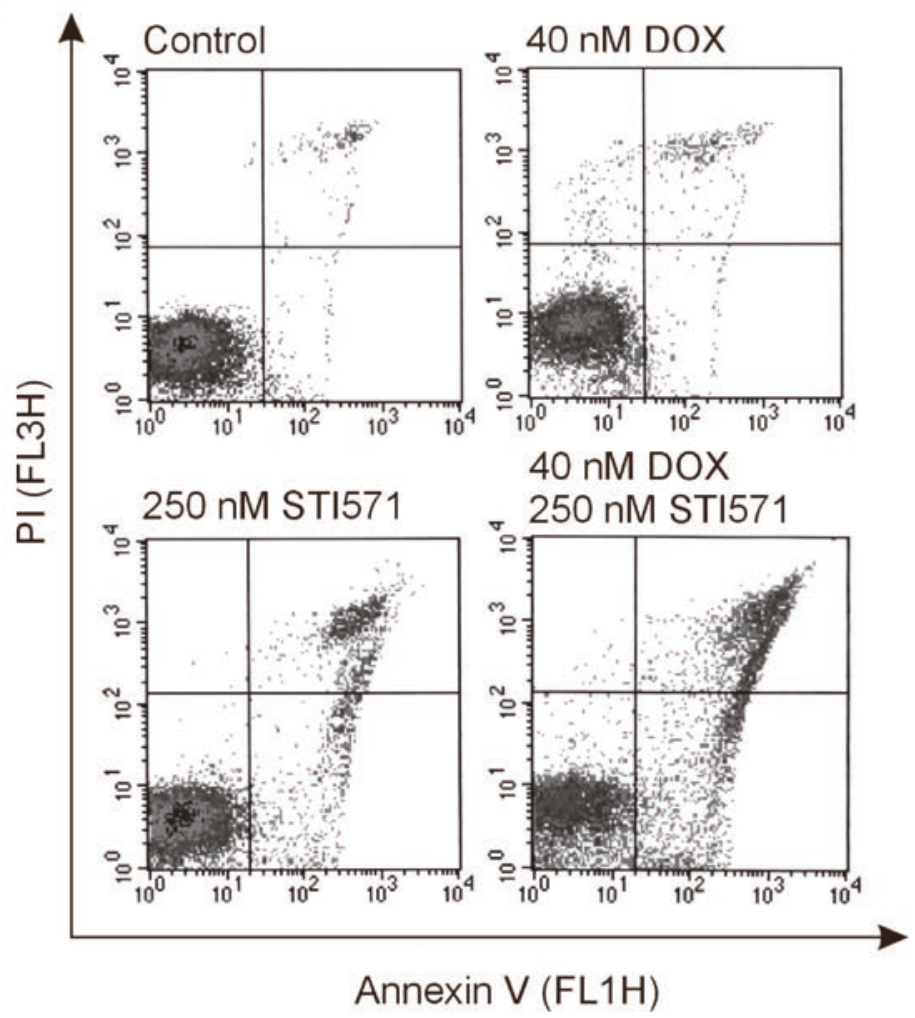

B

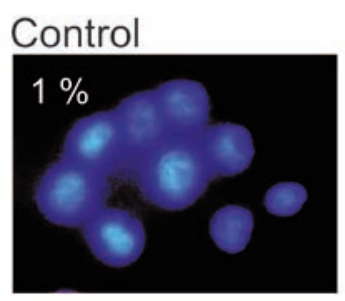

$40 \mathrm{nM}$ DOX

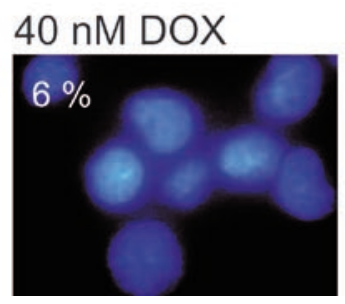

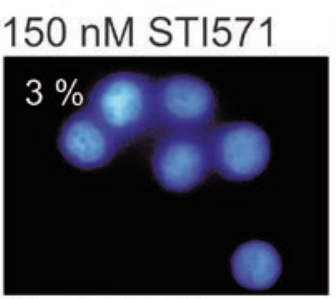

\section{0 nM STI571}

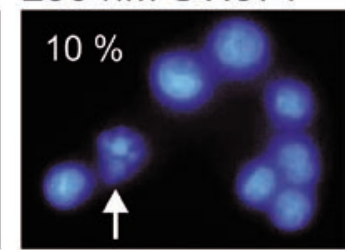

$40 \mathrm{nM}$ DOX 150 nM STI571

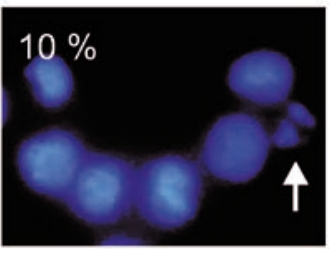

\section{$250 \mathrm{nM}$ STI571}

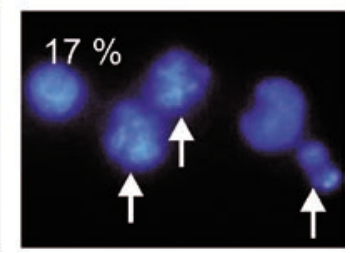

Figure 4. STI57-induced apoptosis is enhanced by DOX.

A. Cells were treated with the indicated concentrations of STI571 and DOX for 2 days, and the percentage of apoptotic cells was determined by Annexin V / propidium iodide staining followed by flow cytometry. Selected histograms are presented. Means \pm S.D. of 2 independent experiments are presented in Table 1. B. Cells were incubated for 2 days with $250 \mathrm{nM}$ STI571 and 40 nM DOX, used alone or in combination. K562 cells were then stained with DAPI for nuclear fragmentation and analyzed by fluorescence microscopy. Arrows indicate examples of cells with fragmented nuclei. Ten different fields were randomly selected for counting 300 cells and the percentage of cells with fragmented nuclei was calculated. Two independent experiments were performed and the S.D. values were not higher than $20 \%$ of the mean values except for control cells where $1.6 \pm 0.5 \%$ was obtained. analyzed by Annexin V staining. Annexin V binds to phosphatidylserine that is exposed on the surface of apoptotic but not normal cells. The results were analyzed by flow cytometry on day 2 (Table 1). Typical histograms are shown in Fig. 4A. Since K562 cells are apoptosis reluctant, a very low percentage of apoptotic cells, close to that observed in control culture was obtained in cultures treated with DOX even at $100 \mathrm{nM}$ where only $9 \%$ of apoptotic cells were observed (not shown). Induction of apoptosis by STI571 was concentration dependent. At 250 nM,
STI571 increased Annexin V positive cells to 16\% and in combination with $40 \mathrm{nM}$ DOX to $30 \%$. This indicates that $250 \mathrm{nM}$ STI571 could sensitize the Bcr-Abl-positive cells to the anticancer drug DOX. Similar results were obtained after DAPI staining. An almost double increase in the percentage of cells with fragmented nuclei was observed in cell cultures treated with $250 \mathrm{nM}$ STI571 in combination with 40 nM DOX compared with those treated with $250 \mathrm{nM}$ STI571 alone (Fig. 4B). But in DAPI staining in comparison to Annexin $\mathrm{V}$ staining, a marked increase in 
A
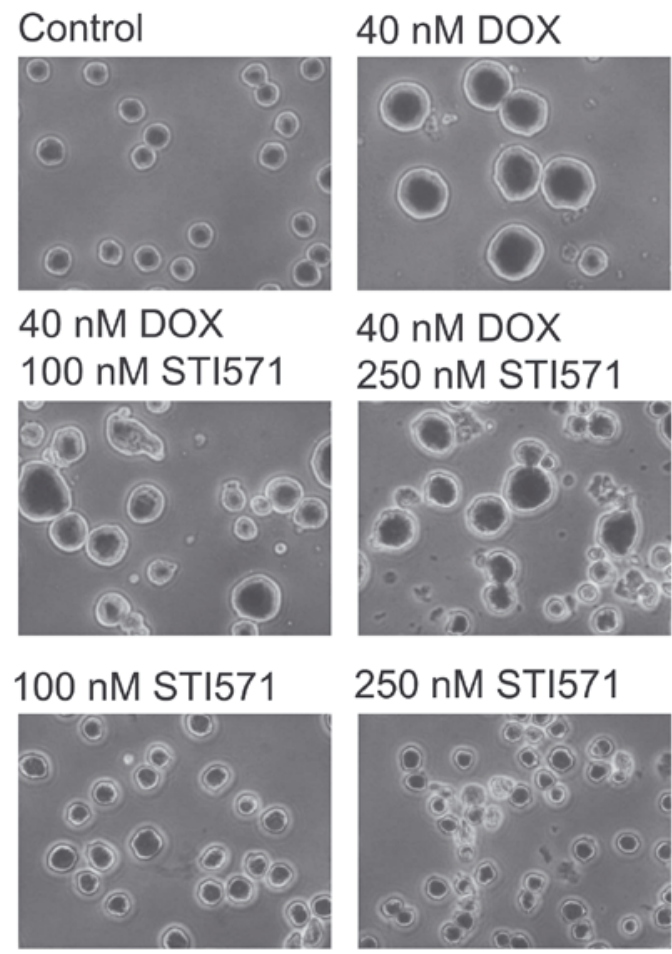

B

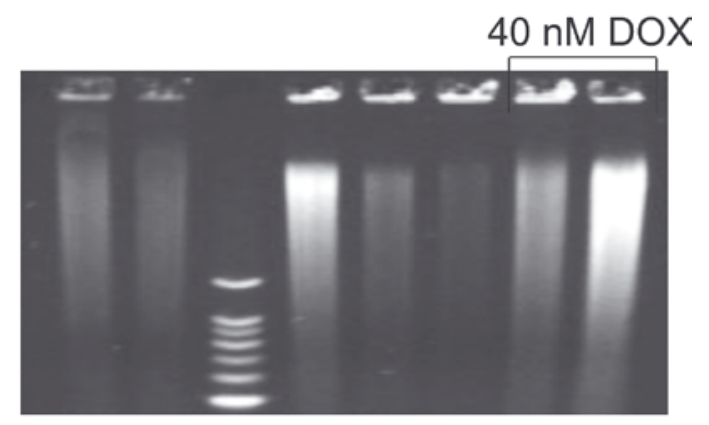

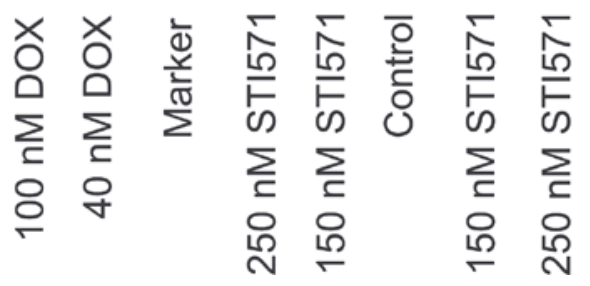

Figure 5. Effects of DOX and STI571 used alone or in combination on K562 cell morphology and DNA fragmentation.

A. Cells were incubated for 3 days with two concentrations of STI571 (100 nM or $250 \mathrm{nM})$ in the absence or presence of $40 \mathrm{nM}$ DOX. Cells were then stained with MayGrünwald-Giemsa and analyzed using light microscope BX 41 (Olympus). B. Low molecular-weight DNA (fragmented DNA) was extracted from untreated and drugtreated cells and subjected to $1.2 \%$ agarose electrophoresis.

the percentage of apoptotic cells was already visible when STI571 at the concentration of $150 \mathrm{nM}$ was used in combination with DOX.
Typical morphological features of apoptosis, such as cell surface blebbing, were also observed under light microscopic examination of K562 cells treated for 3 days with $40 \mathrm{nM}$ DOX in combination with $250 \mathrm{nM}$ STI571 (Fig. 5A). DNA degradation was observed in cells treated with $250 \mathrm{nM}$ STI571 alone or in combination $40 \mathrm{nM}$ DOX (Fig. 5B). The combined treatment enhanced DNA degradation.

It can be concluded that the cell death-inducing activity of DOX on the K562 cells might originate from the action of STI571. This inhibitor, when used at sufficiently high concentrations, could inhibit the kinase activity of Bcr-Abl to the level which allows subsequent induction of death pathways by DOX.

\section{DISCUSSION}

K562 cells, derived from a patient with CML in blast crisis, are Bcr-Abl-positive. A p210 ${ }^{\mathrm{BCR}-\mathrm{ABL}}$-mediated protection of those cells from the induction of apoptosis by cytotoxic drugs has been reported. The current work was done to evaluate the combined effect of continuous exposure to low concentrations of STI571 (100-250 nM) and DOX (mainly $40 \mathrm{nM}$ ) on K562 cells. Except for (Fang et al., 2000), where some effects of high concentrations of DOX $(250 \mathrm{nM})$ in combination with STI571 were analyzed, no other paper has presented this issue. Notably, such a high concentration of DOX as $250 \mathrm{nM}$ is above levels that can be sustained in patients undergoing anticancer therapy (Gewirtz, 1999). STI571 specifically inhibits the activity of some tyrosine kinases, especially the Bcr-Abl kinase (Druker et al., 1996). Depending on DOX concentrations different targets, e.g. DNAtopoisomerase II complex, DNA and RNA polymerases, helicase and secondary effects caused by free radicals production were considered (Gewirtz, 1999). In previously published paper (Fang et al., 2000), 250 nM DOX induced apoptosis in about $27 \%$ of K562 cells as determined by cell morphology only and this percentage was increased to about $40 \%$ when simultaneously $250 \mathrm{nM}$ STI571 was used. It was shown that $250 \mathrm{nM}$ STI571 in combination with 250 nM DOX activated the cleavage of procaspase- 8 and Bid processing which was followed by an increase in the cytosolic cytochrome $c$.

In the current experiments, K562 cells were also susceptible to the inhibitory effects of STI571 and DOX tested alone. We mainly used DOX at 40 $\mathrm{nM}$ but also at lower sub-toxic concentrations.

Our results clearly indicated that STI571 could sensitize the Bcr-Abl-positive K562 cells to cell death induced by a low concentration of the anticancer agent DOX. Similar results, although not discussed in a similar way, were obtained for STI571 used in combination with mycophenolic acid (MPA) (Gu et 
al., 2005). MPA as a specific inosine monophosphate dehydrogenase inhibitor causes the depletion of intracellular guanosine. Since DOX and MPA are unrelated compounds, both in their structures and the mode of action, the similarity in the obtained results should be rather connected with the ability of STI571 to influence the kinase activity of Bcr-Abl. Only a narrow range of concentrations of STI571 causing an inhibition of the Bcr-Abl activity might efficiently support other drugs in the induction of apoptosis. Lower concentrations of STI571 could enhance different cellular processes. STI571 at concentrations lower than $150 \mathrm{nM}$ combined with DOX at 15 to 40 $\mathrm{nM}$ enhanced erythroid differentiation of K562 cells.

Whether this combined in vitro activity will translate into better response and survival rates of CML patients must be assessed in clinical trails. It may be especially important to investigate if by decreasing the kinase activity of Bcr-Abl with low concentrations of STI571 it would be possible to sensitize cancer cells from the blast crisis of CML to death induced by doxorubicin. The concentrations chosen in our study were lower than those which could be achieved and sustained in patients undergoing anticancer therapy. The described mechanisms of drug action might be therefore relevant to the clinical effectiveness of STI571 and DOX used in combination. A pharmacokinetic study has shown that the mean steady state plasma concentration of STI571 inducing hematological and cytogenetic response in patients with CML is about $4.4 \mu \mathrm{M}$ after treatment for 28 days with $400 \mathrm{mg}$ of STI571/day (Peng et al., 2005). The concentrations of STI571 used in the current in vitro study were in the range of $0.1-0.25 \mu \mathrm{M}$, which is much lower than the steady state concentration reported in plasma. Thus, the results of experiments presented in this study, although obtained in vitro, could be applicable to CML patients whose treatment regimens include continuous exposure to STI571. The patients could benefit from lower or less frequent doses of STI571 in many ways, but preventing the emergence of resistant clones should be mainly considered. In addition, DOX is a drug with wellknown dose-toxicity relationships and therefore there is an information available to design clinical trails. Some encouraging results have already been obtained in clinics for combination of STI571 and chemotherapeutic agents. Doxorubicin (Thomas et al., 2004) and daunorubicin (Towatari et al., 2004) were among those chemotherapeutic drugs tested. In both cases, however, patients with $\mathrm{Ph}^{+} \mathrm{ALL}$ not CML were enrolled in the study and in addition doxorubicin was a part of hyper-CVAD (cyclophoshamide, vincristine, doxorubicin, and dexamethasone) regimen and therefore, both remission and toxicity data could be different.
Side effects are an important issue affecting therapeutic decisions. Based on already published results, cardiotoxicity or neutropenia should be taken into account when STI571 and DOX are considered in combined treatment. In mice treated with STI571 in combination with idarubicin, another anthracycline derivative, a more severe neutropenia was induced when compared with that of mice treated with idarubicin alone (Ruchatz et al., 2003). It is well known that cardiomyopathy and congestive heart failure could be developed after completion of cumulative anthracycline regimens (Steinherz et al., 1991). The risk of the development of those side effects correlated with patient age, total DOX dose and dose schedule (for a review: Minotti et al., 2004). STI571 in turn could cause congestive heart failure in a small percentage of CML patients, and STI571treated mice developed left ventricular contractile dysfunction (Kerkelä et al., 2006). The question if a combination of STI571 and DOX at much lower concentrations would enhance only the anticancer efficacy or in addition the already known side effects such as neutropenia or cardiotoxicity, remains to be answered.

\section{Acknowledgements}

The authors wish to thank Dr. Markus Duchler for stimulating discussions and helpful comments, Dr. Irena Oszczapowicz and Mrs. Malgorzata Wasowska for DOX synthesis, Dr. Janusz Blasiak for supplying STI571. We are grateful to Mrs. Grazyna Kus and Izabela Zalesna for technical assistance.

This research was supported by Grant N401 116 31/2630 from the Ministry of Scientific Research and Higher Education and by Grant 502-11444 from the Medical University of Lodz.

\section{REFERENCES}

Bedi A, Barber JP, Bedi GC, el-Deiry WS, Sidransky D, Vala MS, Akhtar AJ, Hilton J, Jones RJ (1995) BCR-ABL-mediated inhibition of apoptosis with delay of G2/M transition after DNA damage: a mechanism of resistance to multiple anticancer agents. Blood 86: 1148-1158.

Czyz M, Szulawska A, Bednarek AK, Duchler M (2005) Effects of anthracycline derivatives on human leukemia K562 cell growth and differentiation. Biochem Pharmacol 70: 1431-1442.

Druker BJ, Tamura S, Buchdunger E, Ohno S, Segal GM, Fanning S, Zimmermann J, Lydon NB (1996) Effects of a selective inhibitor of the Abl tyrosine kinase on the growth of Bcr-Abl positive cells. Nat Med 2: 561-566.

Du Y, Wang K, Fang H, Li J, Xiao D, Zheng P, Chen Y, Fan H, Pan X, Zhao C, Zhang Q, Imbeaud S, Graudens E, Eveno E, Auffray C, Chen S, Chen Z, Zhang J (2006) Coordination of intrinsic, extrinsic, and endoplasmic reticulum-mediated apoptosis by imatinib mesylate combined with arsenic trioxide in chronic myeloid leukemia. Blood 107: 1582-1590. 
Faderl S, Kantarjian H, Talpaz M (1999) Chronic myelogenous leukemia: update on biology and treatment. Oncology 13: 169-180.

Fang G, Kim CN, Perkins CL, Ramadevi N, Winton E, Wittmann S, Bhalla KN (2000) CGP57148B (STI-571) induces differentiation and apoptosis and sensitizes BcrAbl-positive human leukemia cells to apoptosis due to antileukemic drugs. Blood 96: 2246-2253.

Gewirtz DA (1999) A critical evaluation of the mechanisms of action proposed for the antitumor effects of the anthracycline antibiotics adriamycin and daunorubicin. Biochem Pharmacol 57: 727-741.

Gong J, Traganos F, Darzynkiewicz Z (1994) A selective procedure for DNA extraction from apoptotic cells applicable for gel electrophoresis and flow cytometry. Anal Biochem 218: 314-319.

Gu JJ, Santiago L, Mitchell BS (2005) Synergy between imatinib and mycophenolic acid in inducing apoptosis in cell lines expressing Bcr-Abl. Blood 105: 3270-3277.

Kerkelä R, Grazette L, Yacobi R, Iliescu C, Patten R, Beahm C, Walters B, Shevtsov S, Pesant S, Clubb FJ, Rosenzweig A, Salomon RN, Van Etten RA, Alroy J, Durand JB, Force T (2006) Cardiotoxicity of the cancer therapeutic agent imatinib mesylate. Nat Med 12: 908-916.

Minotti G, Menna P, Salvatorelli E, Cairo G, Gianni L (2004) Anthracyclines: molecular advances and pharmacologic developments in antitumor activity and cardiotoxicity. Pharmacol Rev 56: 185-229.

Peng B, Lloyd P, Schran H (2005) Clinical pharmacokinetics of imatinib. Clin Pharmacokinet 44: 879-894.

Pfaffl MW, Horgan GW, Dempfle L (2002) Relative expression software tool (REST) for group-wise comparison and statistical analysis of relative expression results in real-time PCR. Nucleic Acids Res 30: e36.
Ruchatz H, Puttini M, Cleris L, Pilotti S, Gambacorti-Passerini C, Formelli F (2003) Effect of imatinib on haematopoietic recovery following idarubicin exposure. Leukemia 17: 298-304.

Schindler T, Bornmann W, Pellicena P, Miller WT, Clarkson B, Kuriyan J (2000) Structural mechanism for STI571 inhibition of abelson tyrosine kinase. Science 289: 1938-1942.

Steinherz LJ, Steinherz PG, Tan CTC, Heller G, Murphy L (1991) Cardiac toxicity 4 to 20 years after completing anthracycline therapy. JAMA 266: 1672-1677.

Szulawska A, Arkusinska J, Czyz M (2007) Accumulation of gamma-globin mRNA and induction of irreversible erythroid differentiation after treatment of CML cell line K562 with new doxorubicin derivatives. Biochem Pharmacol 73: 175-184.

Thiesing JT, Ohno-Jones S, Kolibaba KS, Druker BJ (2000) Efficacy of STI571, an abl tyrosine kinase inhibitor, in conjunction with other antileukemic agents against bcrabl-positive cells. Blood 96: 3195-3199.

Thomas Thomas DA, Faderl S, Cortes J, O’Brien S, Giles FJ, Kornblau SM, Garcia-Manero G, Keating MJ, Andreeff M, Jeha S, Beran M, Verstovsek S, Pierce S, Letvak L, Salvado A, Champlin R, Talpaz M, Kantarjian H (2004) Treatment of Philadelphia chromosome-positive acute lymphocytic leukemia with hyper-CVAD and imatinib mesylate. Blood 103: 4396-4407.

Towatari M, Yanada M, Usui N, Takeuchi J, Sugiura I, Takeuchi M, Yagasaki F, Kawai Y, Miyawaki S, Ohtake S, Jinnai I, Matsuo K, Naoe T, Ohno R (2004) Combination of intensive chemotherapy and imatinib can rapidly induce high-quality complete remission for a majority of patients with newly diagnosed BCR-ABL-positive acute lymphoblastic leukemia. Blood 104: 3507-3512. 